\title{
The Classical Notion of Competition Revisited
}

\author{
Neri Salvadori and Rodolfo Signorino
}

The gravitation of market prices toward natural prices in all markets characterized by free competition was widely affirmed by the classical authors, despite the lack of a formal proof. In the wake of the revival of interest in classical economics fostered by the publication of Production of Commodities by Means of Commodities (Sraffa 1960), since the mid-1970s a vast literature has blossomed concerning the stability of long-period equilibrium within multisectoral models of classical inspiration. (For a survey of this literature, see Bellino 2011.) Besides the formal results achieved on the subject of stability, the debate on gravitation has stimulated an indepth investigation of the classical notion of market competition (Arena 1978; Semmler 1984; Steedman 1984; Duménil and Lévy 1987). This investigation has also highlighted some unsatisfactory aspects in the latter, particularly the actual process of market price determination in a situation of market disequilibrium:

Correspondence may be addressed to Neri Salvadori, Dipartimento di Scienze Economiche, Università di Pisa, via Cosimo Ridolfi 10, 56124, Pisa, Italy; e-mail: nerisal@ec.unipi.it. The article was prepared for the Italian National Research Project, cofinanced by the Italian Minister of University, "Heterogeneous Sectors, Growth, and Technical Change" (2007). A previous version of this article was presented at the thirteenth annual conference of the European Society for the History of Economic Thought, Thessaloniki, Greece, April 23-26, 2009, and at the seventh annual conference of the Italian Association for the History of Political Economy, Trento, Italy, May 30-June 1, 2010. We wish to thank Alain Alcouffe, Enrico Bellino, Stefano Fiori, Heinz D. Kurz, Manuela Mosca, Arrigo Opocher, and Maria Pia Paganelli for their comments. The usual caveats apply.

History of Political Economy 45:1 DOI 10.1215/00182702-1965222

Copyright 2013 by Duke University Press 
Little is said concerning the actual process [which governs the functioning of the market for commodities]. For example, it is not clear who is changing prices, what information is used, when this change occurs, what the outcome is on the market etc. (Duménil and Lévy 1987, 136)

[L'originalità della teoria classica della libera concorrenza] non è però in grado di nascondere certe insufficienze: l'economia politica classica si scontra infatti con il problema centrale dell'articolazione tra prezzi di mercato e prezzi naturali. La soluzione di queste difficoltà richiede una nuova definizione di questa articolazione. (Arena 1978, 323) ${ }^{1}$

The aim of this article is to detect and highlight those elements present in classical texts that may be fruitfully employed to overcome the above drawbacks of the classical view of market competition. Moreover, as recent commentators of classical economics have emphasized, in a situation of disequilibrium, when the quantity of a given commodity brought to the market differs from Smithian effectual demand, the likely outcome is that of a dispersion of prices: "Whereas natural price is by definition a singular magnitude for each kind of commodity, the competitive processes whereby market prices deviate from natural price under conditions of market imbalance are consistent with, indeed likely to cause, transactions at nonuniform prices. That is to say, market price as literally the actual prices at which transactions occur when there is such market imbalance, is not in general a singular magnitude" (Aspromourgos 2009, 72; see also pages 85 and 88). Accordingly, we claim that the classical theory of market prices gives scope to the analysis of the behavior of the agents acting in situations of market imbalance through some of the analytical tools and formal results achieved by the modern game-theoretic approach to oligopoly theory, namely, the notion of mixed (i.e., nondeterministic) price-strategy.

In what follows, we distinguish and compare two different conceptions of market competition: the Walrasian notion of perfect competition and the classical notion of free competition, focusing in particular on Adam Smith and Karl Marx. We stress that while the Walrasian notion may be described as an equilibrium state in which atomistic agents treat prices parametrically, the classical notion is a situation in which agents employ their market power by setting prices strategically. The absence of a price-

1. [The originality of the classical theory of free competition] is not, however, able to hide certain inadequacies: the classical political economy clashes with the central problem of the articulation between market prices and natural prices. The solution of such difficulties requires a new definition of this articulation (our translation). 
taking assumption in the classical authors is the main reason why the theoretical difficulties besetting the Walrasian notion outside marketclearing equilibrium do not plague the classical notion as well. Yet though for the classical authors price undercutting or outbidding are the typical phenomena that occur in any market characterized by free competition, it is fair to say that they went no farther than to provide only some unsystematic guidelines on how to analyze in due detail the competitive process of market price determination. Among other things, we show that Marx's extensive use of metaphors and numerical examples hides the modern taxonomy of buyers' market, sellers' market, and mixed strategy equilibrium in the capacity space of a standard Bertrand duopoly model. In particular, we argue that Marx was conscious that between the buyers' market, in which the price is determined by the reservation price of sellers, and the sellers' market, in which the price is determined by the reservation price of buyers, there is something in which the price is not unique and any equilibrium can concern only distributions of probability (mixed strategies) on the behavior of the traders. We substantiate this fact by using a formalism derived from the contemporary analysis of Bertrand competition. (The elements required to identify a necessary and sufficient condition to separate these three different market outcomes are sketched in an appendix.) We are aware that our analysis, once duly developed, needs to be related to contemporary gravitation literature. Yet we defer investigation of this issue to a future paper. ${ }^{2}$

The structure of the article is as follows. Section 1 compares two different notions of the concept of market competition, the classical notion of free competition and the neoclassical notion of perfect competition, and highlights some problematic aspects of the latter, absent in the former. Sections 2 and 3 assess the classical theory of free competition, as developed by Adam Smith and Karl Marx, with particular concern for market price determination. Section 4 investigates how the classical notion of competition has percolated into the modern literature on so-called Bertrand competition. Section 5 concludes.

2. The basic model used to represent the classical gravitation process is the so-called cross-dual model, in which (1) sectoral outputs change in response to differentials in the rates of profit; (2) market prices change in response to excess demand of the various commodities. While the first adjustment process is widely accepted as a fair formalization of the classical principle of capital mobility, the second appears as a mechanical transposition of the Walrasian price adjustment process and is the ultimate culprit behind the intrinsic instability of cross-dual gravitation processes. The present article proposes a totally different market price formation and should be able to resolve the instability problem envisaged in this literature. 


\section{Two Different Notions of Market Competition or Just One?}

Few commentators would disagree with the following statement: "Although the concept of competition has always been central to economic thinking ... it is one that has taken on a number of interpretations and meanings, many of them vague" (Vickers 1995, 3). In particular, Vickers distinguishes the notion of perfect competition - a "seemingly tranquil equilibrium state in which well-informed agents treat prices parametrically"-from the "original and 'real' concept" of competition, a "rivalrous behaviour with respect to prices and other variables in a world characterized by flux, uncertainty and disequilibrium" (7).

Despite the differences between these two notions, many authors have come (more or less explicitly) to consider the classical notion of free competition nothing but a primitive and pre-analytical version of the neoclassical theory of perfect competition, a version still imbued with casual empiricism: "It is a remarkable fact that the concept of competition did not begin to receive explicit and systematic attention in the main stream of economics until 1871. This concept ... was long treated with the kindly casualness with which one treats of the intuitively obvious. . . 'Competition' entered economics from common discourse, and for long it connoted only the independent rivalry of two or more persons" (Stigler 1957, 1). Such an interpretation has deeply influenced many of the leading exponents of neoclassical economics. (See, e.g., Arrow and Hahn 1971, in particular chapter 1, "Historical Introduction," and Samuelson 1978.) Even outside the neoclassical camp this interpretation has found supporters, such as Nicholas Kaldor (1972, 1241), when he claims that "one can trace a more or less continuous development of price theory from the subsequent chapters of Smith [the fourth chapter of the Wealth of Nations] through Ricardo, Walras, Marshall, right up to Debreu and the most sophisticated of present-day Americans." Vickers $(1995,7)$ himself concludes that "the claim that there are two concepts of competition is somewhat misleading."

Nonetheless, historians of economic thought who have endorsed an alternative point of view have not been lacking. Paul McNulty $(1967,397)$ not only argued that the classical notion of competition as a behavioral process is radically different from the neoclassical notion of competition as an equilibrium state but also went so far as to claim that the neoclassical assumption of individual price-taking behavior is entirely alien to 
the classical analysis: " "Smith's concept of competition was decidedly not one in which the firm was passive with respect to price but was, rather, one in which the market moved toward equilibrium through the active price responses of its various participants." Therefore, what in the previous interpretation appears simply as a process of analytical refinement, in McNulty's view is no less than "a basic conceptual change" (397). Moreover, McNulty adds that, pace George Stigler, the classical notion of competition is far from being derived from casual empiricism. Smith is the great systematizer of the analysis of the concept of market competition carried out by a series of authors before him (most notably, Cantillon and Turgot) and his specific contribution was to raise the concept of competition to a "general organizing principle of economic society. . . . After Smith's great achievement, the concept of competition became quite literally the sine qua non of economic reasoning" (McNulty 1967, 396-97; see also McNulty $1968,646-47){ }^{4}$

McNulty's interpretation raises the matter of investigating the theoretical conditions that have led to such a dramatic change of meaning in the original notion of competition. A first step in this direction may be found in the distinction between two different notions of economic science: (1) economics as the science that studies a system of forces and (2) economics as the science that studies a system of relations-a distinction introduced by Marco Dardi (1983) that was recently emphasized by Nicola Giocoli (2005):

According to the system-of-forces (SOF) view, economics is a discipline whose main subject is the analysis of the economic processes

3. From this point of view, McNulty's interpretation is akin to those of Samuel Hollander (1973) and John Eatwell (1987). The former claims that "the Smithian conception of competition must be carefully distinguished from the modern conception which envisages sellers (and consumers) as 'price-takers' rather than 'price-makers"” (126), while the latter points out that "the characteristics of 'perfect' competition (notably the conditions which ensure price-taking) are often read back, illegitimately, into Classical discussions of competition" (63). See also High 2001, xiv-xv; and Machovec 2005, chap. 8. While Blaug defines Arrow and Hahn's 1971 tribute to Adam Smith as a forerunner of perfect competition (and Pareto optimality) analysis no less than "a historical travesty" (Blaug 2001, 153), a more balanced position is endorsed by Michael Bradley $(2010,238)$, who argues that "Smithian 'liberty' contains the seeds of perfect competition, but perfect competition is different from 'perfect liberty' in some critical respects, particularly the nature of competition and the role of entrepreneurs."

4. McNulty (1967, 395-96) provides a discussion of Cantillon and Turgot as forerunners of Smith on competition. An extensive treatment of the evolution of the notions of price, cost, and competition before Smith may be found in Aspromourgos 2009, 101-10. 
generated by market and not-market forces, including-but by no means exclusively-the processes leading the system to an equilibrium. According to the system-of-relations (SOR) view, economics is a discipline whose main subject is the investigation of the existence and properties of economic equilibria in terms of the validation and mutual consistency of given formal conditions, but that has little if anything to say about the meaningfulness of these equilibria for the analysis of real economic systems. (Giocoli 2005, 180)

According to Giocoli, the SOF view was the dominant vision up to the years between the two world wars, while the SOR view gained popularity only in the second postwar period when considerable intellectual effort was devoted to the project of a full axiomatization of economic science (180). Similarly, in a series of papers Blaug $(1997,2002$, and 2003) indicated in the formalist revolution of the 1950s and the parallel rise to dominance of the Walrasian general equilibrium theory the two driving forces that led to the decline of the classical (and early neoclassical) notion of competition as a process and its replacement with the modern notion of competition as an end-state (with the associated first and second fundamental theorems of welfare economics).

Thus it may be claimed that the semantic shift in the notion of competition is part of a more general process of redefining central categories and concepts of economic analysis started in the 1930s with the rediscovery of Walrasian general equilibrium theory (Donzelli 1990, chap. 9) and fully accomplished in the late 1970s with the rediscovery of the Nash equilibrium concept (Giocoli 2003, chap. 5): the classical notion of market competition makes little sense outside the SOF view, while the Walrasian notion of competition perfectly fits the theoretical standards set by the SOR view.

There are at least two reasons why the distinction between the classical notion of competition and the neoclassical one and careful analysis of the theoretical domain of the latter is not simply a historiographical exercise:

1. The neoclassical theory of perfect competition carries with it some theoretical difficulties alien to the classical notion of free competition.

2. The classical notion of competition can be made analytically precise in terms of the modern concept of mixed strategies equilibrium.

The final part of this section is devoted to substantiating point 1 above, while we defer analysis of point 2 to section 4 . 
As pointed out by Jerry Green (1974), every market equilibrium concept requires the specification of a consistent set of behavioral postulates that prescribe what happens in equilibrium and what happens outside equilibrium. In the Walrasian framework, the behavioral postulates that define the situation of equilibrium differ from those that define the adjustment mechanism in disequilibrium. As regards the former, the behavioral postulate is that every agent assumes market prices as parametrically given and, on the basis of such prices and other constraints, maximizes his or her own objective function. By contrast, in disequilibrium, the behavioral postulate is that a meta-agent, the auctioneer, determines market prices according to market excess demands. Moreover, no transactions among the agents are allowed to take place during the adjustment process. ${ }^{5}$ As a consequence, the price-taking behavior assumption implies that each individual firm in a given market has no incentive to set a price different from the ruling market price and has no incentive to carry on transactions at a price other than the Walrasian market-clearing price. Thus such an assumption drastically reduces the theoretical domain of the theory to equilibrium, market-clearing situations. ${ }^{6}$

To our knowledge, Kenneth Arrow (1959) was the first to highlight the logical difficulties besetting the neoclassical theory of perfect competition:

the Law [of supply and demand, Arrow's equation 3: $d p / d t=h(S-D)$ with $h^{\prime}<0$ and $h(0)=0$ ] is not on the same logical level as the hypotheses underlying equation $1[D=f(p)$ and $S=g(p)]$. It is not explained whose decision it is to change prices in accordance with equation 3 .

5. From this perspective Edgeworth's concept of equilibrium (core) and his adjustment process in disequilibrium (recontracting) are superior to the Walrasian ones: "The recontracting process . . . is based on the same behavioral postulate, blocking by coalitions, that is used to define the solution concept, the core [The core is defined to be the set of all unblocked allocations. That is, it is the set of all allocations such that no subset of the participants can improve the position of all its members by withdrawing from the system and using only resources of its members]. This seems to be a desirable property. It is, however, not shared by most studies of disequilibrium price dynamics because these involve price changes brought about by a market manager or other artificiality. Prices do not vary as a consequence of the maximizing behavior of individuals" (Green 1974, 22).

6. Current textbooks also acknowledge this fact: "Strictly speaking, it is equilibrium market prices that [consumers and producers] will regard as unaffected by their actions. . . . For the price-taking assumption to be appropriate, what we want is that [consumers and producers] have no incentive to alter prices that, if taken as given, equate demand and supply (we have already seen that [consumers and producers] $d o$ have an incentive to alter prices that do not equate demand and supply) (Mas-Colell, Whinston, and Green 1995, 314n1, 315; emphasis added). 
Each individual participant in the economy is supposed to take prices as given and determine his or her choices as to purchases and sales accordingly; there is no one left over whose job it is to make a decision on price. (Arrow 1959, 43)

In short, for Arrow in the perfect competition setup there is no place left for "a rational decision with respect to prices" thus implying the conclusion that "perfect competition can really prevail only at equilibrium" (41). The solution proposed by Arrow to study market price dynamics outside market-clearing equilibrium consists in turning to the theory of the monopoly: "When supply and demand do not balance, even in an objectively competitive market, the individual firms are in the position of monopolists as far as the imperfect elasticity of demand for their products is concerned" (46). However, Arrow claims that standard monopoly theory must be modified so as to remove the assumption that monopolists know perfectly their own demand curve (besides their own cost curves): "Uncertainty [as to the demand curve] is a crucial consideration in the theory of monopolistic price adjustment" (44). In such circumstances, monopolists will vary their own price, in a process of trial and error, until they find the price that maximizes their expected profits.

For our purpose, the salient points of Arrow's analysis are the following:

1. Jevons' law of indifference, which states that there is only one price ruling in a competitive market, ceases to be valid in disequilibrium: "Although the broad tendency will be for prices to rise when demand exceeds supply, there can easily be a considerable dispersion of prices among different sellers of the same commodity" (46-47).

2. By assuming that competition takes place on both sides of the market, that is, competition among sellers and competition among buyers, a buyers' market may be distinguished from a sellers' market: "By a parallel argument each buyer on a market with an inequality between supply and demand can be regarded as a monopsonist. . . . In disequilibrium, the market consists of a number of monopolists facing a number of monopsonists. The most general picture is that of a shifting set of bilateral monopolies. . . In general, it is reasonable to suppose that if the selling side of the market is much more

7. $D(S)$ is the quantity demanded (supplied) of a given commodity $X, p$ its price, $f(p)$ and $g(p)$ the demand and supply functions, respectively, while $d p / d t=h(S-D)$ is the time derivative that formalizes the law of motion of market price in relation to market excess demand. 
concentrated than the buying side, the main force in changing prices will be the monopolistic behavior of the sellers. . . . Similarly, if the buying side of the market is the more concentrated, as in non-unionized labor markets, the dynamics will come from that side" (47; emphasis added).

In the following two sections we make it clear that these two elements of Arrow's contribution may be found in Smith's and, even more explicitly, in Marx's treatment of market prices, thus paving the way for a restatement of the classical notion of competition through contemporary gametheoretic analysis. ${ }^{8}$

\section{The Classical Notion of Free Competition: Adam Smith}

George Richardson $(1975,350-51)$ has convincingly argued that "competition features within The Wealth of Nations in two different contexts; first, in the account given of the balancing of supply and demand in particular markets, and, secondly, in the explanation of structural and technological development. Smith offers us in effect both a theory of economic equilibrium and a theory of economic evolution; and in each of these competition has a key role to play." In what follows we concentrate on the static aspect of the Smithian notion of market competition, concerned with market price determination, leaving aside its dynamic aspect (see Lavezzi 2003).

As far as the classical notion of market competition is concerned, the locus classicus is book 1, chapter 7 of Smith's ([1776] 1976) Wealth of Nations $(W N) .{ }^{9}$ Smith's working assumption is that it is possible to classify the economic forces in action in a given moment into two broad categories, (1) those erratic and short-lived forces that determine the market values both of commodity prices and of the distributive variables and (2) those systematic and persistent that determine the natural values of the same magnitudes. Classical economists generally hold the view that

8. Arrow's 1959 contribution with its emphasis on the role of monopoly theory in explaining competitive price convergence is the ideal starting point for the subsequent neo-Walrasian literature on disequilibrium trading (see Donzelli 1990, chap. 9).

9. As is well known, Ricardo $(1951,91)$ devotes to the distinction between natural and market magnitudes just the short chapter 4 of his Principles, where he explicitly refers to chapter 7 of $W N$, where "all that concerns this question is most ably treated." 
only the latter can be the proper subject of scientific inquiry (Ciccone 1999, 70). ${ }^{10}$

The data from which the Smithian argument starts are the natural rates of wages, profits, and rents that, sectoral specificities apart, depend mainly on the conditions of prosperity of the economic system under scrutiny, its "advancing, stationary, or declining condition" (WN I.vii.1). The natural price of (re)production of the various commodities derives from the summation of these three elements. The natural price is therefore a magnitude that is not immediately formed in the market but that, given some appropriate conditions, may come true in the market. Indeed, the natural price constitutes a sort of a floor for the market price in the sense that the latter cannot remain for long below the former without seriously jeopardizing the reproduction of the commodity in question: "The competition of the different dealers obliges them all to accept of [the natural price]; but does not oblige them to accept of less. ... The natural price, or the price of free competition ... is the lowest which can be taken, not upon every occasion, indeed, but for any considerable time together ... is the lowest which the sellers can commonly afford to take, and at the same time continue their business" (WN I.vii.11). The theoretical importance of natural prices consists in providing a guide to the theorist for explaining the dynamic path followed by market prices: "The natural price, therefore, is, as it were, the central price to which the prices of all commodities are continually gravitating. Different accidents may sometimes keep them suspended a good deal above it, and sometimes force them down even somewhat below it. But whatever may be the obstacles which hinder them from settling in this center of repose and continuance, they are constantly tending towards it" (WN I.vii.15).

To study the genesis of market prices and the existing relations between market prices and natural prices, Smith introduces the concept of effectual demand, that is, "the demand of those who are willing to pay the natural price of the commodity." It is to be stressed that the relationship between the quantity brought to the market and the effectual demand

10. Ricardo (1951, 91-92) clearly states that the focus of his analysis is only natural magnitudes: "Having fully acknowledged the temporary effects which, in particular employments of capital, may be produced on the prices of commodities, as well on the wages of labour, and the profits of stock, by accidental causes, without influencing the general prices of commodities, wages or profits, since these effects are equally operative in all stages of society, we will leave them entirely out of consideration, whilst we are treating of the laws which regulate natural prices, natural wages and natural profits, effects totally independent of these accidental causes." 
determines only the market price of a commodity and not also its natural price. ${ }^{11}$ Moreover, "demand" and "supply" are treated by Smith as given quantities and not as functional relationships between price and quantity characterized by well-defined formal properties, as they would be in the neoclassical theory (Garegnani 1983; Aspromourgos 2009, 83-84). ${ }^{12}$

Given the unplanned nature of market economies, at the end of a productive cycle, entrepreneurs may not face in the market a demand able to absorb the whole of their production at the natural price (at least). This requires the specification of an adjustment mechanism powerful enough to bring about effective convergence to a situation in which the produced quantity coincides with the effectual demand: in the absence of such a mechanism, natural prices may not constitute a reliable guide to explain the movements of market prices. ${ }^{13}$

In short, the adjustment mechanism envisaged by classical authors is as follows. At the end of a productive cycle, the entrepreneur brings to the market a given quantity of produced commodity resulting from the production decisions taken at the beginning of the cycle just concluded. Of course, this quantity cannot be modified to adjust to the demand actually encountered on the market. Thus the adjustment variable is constituted by the commodity's selling price. Smith assumes that, in the presence of a gap between production and effectual demand, a sort of auction starts among the agents that happen to be on (what we today would call the) long side of the market: such agents are prepared to offer higher and higher prices (in case of excess demand) or lower and lower prices (in the case of excess supply).

Once the market price of any commodity happens to be different from its natural price, this causes an imbalance in the distributive sphere

11. See Ricardo's (1951, 1:382) rejection of the opinion that price depends solely on the proportion between these two quantities.

12. Differences between the classical and the neoclassical theories of value and distribution have been emphasized by such authors as Krishna Bharadwaj (1978), Alessandro Roncaglia (1978), and Pierangelo Garegnani (1984). Nonetheless, historiographical controversies are still very much alive: see Blaug 1999 and 2009 versus Kurz and Salvadori 2002 and 2010.

13. This consideration may explain Ricardo's (1951 1:90; emphasis added) emphasis on the effectiveness of the adjustment mechanism: "When we look to the markets of a large town, and observe how regularly they are supplied both with home and foreign commodities, in the quantity in which they are required, under all circumstances of varying demand . . . without often producing either the effect of a glut from too abundant a supply, or an enormously high price from the supply being unequal to the demand, we must confess that the principle which apportions capital to each trade in the precise amount that is required, is more active than is generally supposed." 
in the sense that the remunerations of those people that have contributed to the production of the commodity prove different from their respective natural values. In the absence of entry/exit barriers and in the presence of market transparency the difference between the market price and the natural price brings about (1) an intersectoral reallocation of economic resources in search of the highest market remuneration and (2) a variation in the produced quantity of the commodity in the following periods. This process comes to a halt only when the produced quantity and demanded quantity balance in correspondence of the natural price and the market values of wages, profits, and rent equal their respective natural values. ${ }^{14}$ Therefore the imbalance in the sphere of circulation (discrepancy between natural price and market price of a commodity) spills over to the sphere of distribution (discrepancy between natural values and market values of wages, profits, and rent) and, finally, to the sphere of production (intersectoral reallocation of productive resources and variation in quantities produced in the following periods).

The assumed tendency of market values toward their respective natural values is based on two assumptions: (1) the owners of the employed inputs consider, besides the outlay costs, also the opportunity costs in their decisions as to where to allocate their economic resources (Aspromourgos $2009,67,98)$ and (2) there are but negligible barriers to the intersectoral mobility of economic resources (91):

When the price of any commodity is neither more nor less than what is sufficient to pay the rent of the land, the wages of the labour, and the profits of the stock employed in raising, preparing, and bringing it to market, according to their natural rates, the commodity is then sold for what may be called its natural price. The commodity is then sold precisely for what it is worth, or for what it really costs the person who brings it to market; for though in common language what is called the prime costs of any commodity does not comprehend the profit of the person who is to sell it again, yet if he sell it at a price which does not allow him the ordinary rate of profit in his neighbourhood, he is evidently a loser by the trade; since by employing his stock in some other way he might have made that profit. . . . Though the price, therefore, which leaves him this profit is not always the lowest at which the dealer

14. However, classical economists were perfectly aware of the existence of profit and wage rate differentials. For a modern treatment, see Kurz and Salvadori 1995, chapter 11. 
may sometimes sell his goods, it is the lowest at which he is likely to sell them for any considerable time; at least where there is perfect liberty, or where he may change his trade as often as he pleases. (WN I.vii.6; emphasis added)

The above shows that Smith devotes much care to determining natural values and to the gravitation process of market magnitudes to their natural counterparts. The same cannot be maintained as regards the question of market price determination, particularly when the market is not in a situation of long-period equilibrium. Taking stock of Smith's sparse hints on this subject it is possible to point out what follows.

First, in those markets in which competition is not free (e.g., because of legal monopoly and/or the presence of a guild, a collusive agreement, a law or a rule that somehow prevents economic agents allocating their resources in the sector they prefer) or where there are industrial secrets, entrepreneurs voluntarily limit the produced quantity so that the market is left understocked and the market price stays artificially high:

The exclusive privileges of corporations, statutes of apprenticeship, and all those laws which restrain, in particular employments, the competition to smaller number than might otherwise go into them, have the same tendency, though in a less degree. They are a sort of enlarged monopolies, and may frequently, for ages together, and in whole classes of employments, keep up the market price of particular commodities above the natural price, and maintain both the wages of the labour and the profits of the stock employed about them somewhat above their natural rate. (WN I.vii.28)

Conversely, where competition is free and industrial secrets absent, price undercutting starts as soon as at least two competitors are present in the market. This process is amplified by increasing the number of competitors, since this fact makes the establishment of a collusive agreement more unlikely:

The quantity of grocery goods, for example, which can be sold in a particular town is limited by the demand of that town and its neighbourhood. The capital, therefore, which can be employed in the grocery trade cannot exceed what is sufficient to purchase that quantity. If this capital is divided between two different grocers, their competition will tend to make both of them sell cheaper than if it were in the hands of one only; and if it were divided among twenty, their competition would 
be just so much the greater, and the chance of their combining together, in order to raise the price, just so much the less. (WN II.v.7)

Second, Smith's explanation for the determination of market prices in situations of disequilibrium includes not only elements that are seemingly the fruit of a casual observation and that he does not analyze in greater detail (the wealth of the buyers and their desire to get the commodity versus the necessity of the sellers to dispose of their own commodities) but also elements that he instead systematically applies in his analysis of the various markets. Of the latter, the most significant is the relative number of sellers and buyers and their relative ability to make a binding agreement. The market price will be high or low depending on whether buyers are more numerous than sellers (and vice versa): the buyers "bid against one another" offering higher and higher prices, the sellers "bid against one another" offering lower and lower prices. The relative number of the buyers in relation to the sellers is therefore the crucial element: every time that the agents on one side of the market are few and are able to communicate (e.g., because they operate in the same place such as a town) while the agents on the other side of the market are many and are unable to communicate (e.g., because they are isolated and scattered in the countryside), the bargaining from which the market price springs will obviously be more favorable to the former. This is particularly evident in Smith's analysis of the labor market:

What are the common wages of labour, depends every where upon the contract usually made between those two parties, whose interests are by no means the same. The workmen desire to get as much, the masters to give as little as possible. The former are disposed to combine in order to raise, the latter in order to lower the wages of labour. It is not, however, difficult to foresee which of the two parties must, upon all ordinary occasions, have the advantage in the disputes, and force the other into compliance with their terms. The masters, being fewer in number, can combine much more easily; and the law, besides, authorises, or at least does not prohibit their combinations, while it prohibits those of the workmen. . . . When in any country the demand for those who live by wages; labourers, journeymen, servants of every kind, is continually increasing; when every year furnishes employment for to greater number than had been employed the year before, the workmen have no occasion to combine in order to raise their wages. The scarcity of hands occasions a competition among masters, who bid against one another, in order to get workmen, and thus voluntarily break 
through the natural combination of masters not to raise wages. (WN I.viii.11-12, 17)

In the following section we show how Marx draws on and develops these elements of Smith's treatment of market prices.

\section{The Classical Notion of Free Competition: Karl Marx}

In chapter 3 of Wage-Labour and Capital (Marx [1847] 1933) it is possible to find a vivid description of price determination in the market of a raw material, cotton. We think that such a description provides a clue to the young Marx's view of the competitive process. The chapter bears the title "By what is the price of a commodity determined?" and Marx's answer is the quite conventional one: "By the competition between buyers and sellers, by the relation of the demand to the supply, of the call to the offer" (21). Yet, immediately after, he adds that "the competition by which the price of a commodity is determined is threefold" (21; emphasis added). The first element highlighted by Marx is competition among the sellers: "Whoever sells commodities of the same quality most cheaply, is sure to drive the other sellers from the field and to secure the greatest market for himself. . . . [It is competition among the sellers] which forces down the price of the commodities offered by them" (21). The second element is competition among the buyers that "causes the price of the proffered commodities to rise" (21). These two aspects of competition are not considered sufficient to fully determine the outcome of the competitive process. In fact, Marx adds a third and last element:

Finally, there is competition between the buyers and the sellers: these wish to purchase as cheaply as possible, those to sell as dearly as possible. The result of this competition between buyers and sellers will depend upon the relations between the two above-mentioned camps of competitors-i.e., upon whether the competition in the army of sellers is stronger. Industry leads two great armies into the field against each other, and each of these again is engaged in a battle among its own troops in its own ranks. The army among whose troops there is less fighting, carries off the victory over the opposing host. $(21)^{15}$

15. Marx's treatment of competition in this passage echoes James Steuart's notion of double competition. Marx was well acquainted with the work of Steuart, with whom he often took issue (Denis 1999). On Steuart's notion of double competition, see Menudo and Tortajada 2009. 
We claim that the metaphor of the two armies that, at the one and the same time, are engaged in fighting one another and in their own ranks, coupled with the suggestion that the result of the battle is eventually decided by the interplay of these two levels of fighting, paves the way to an interesting analytical intuition. In our view Marx's rhetoric foreshadows the modern notion of a mixed strategy equilibrium: the outcome of market competition needs not be univocally determined, even if optimal (mixed) strategies are.

To clarify his thought Marx goes on to provide a concrete example. Marx's choice of a raw material market for this didactic purpose is illuminating. In the market of a consumption good it is quite obvious to assume a multitude of atomistic buyers. In such a case, competition among buyers would be reduced to their reservation prices and, eventually, described through a demand curve. It may not be so in the case of a raw material market, where the number of buyers may exceed that of sellers, and, in some cases, it is even possible to reverse the image of atomistic buyers to that of atomistic sellers. Marx's example starts with the analysis of what, in modern terminology, is called a sellers' market: "Let us suppose that there are 100 bales of cotton in the market and at the same time purchasers for 1,000 bales of cotton" (21). The fact that the demand is many (ten!) times greater than the supply is very likely to be intentional: if there were 100 bales and purchasers for 110, conditions would have not been, in Marx's opinion, those of a sellers' market. On the contrary, 100 to 1,000 is considered enough to obtain that

the cotton sellers, who perceive the troops of the enemy in the most violent contention among themselves, and who therefore are fully assured of the sale of their whole 100 bales, will beware of pulling one another's hair in order to force down the price of cotton at the very moment in which their opponents race with one another to screw it up high. So, all of a sudden, peace reigns in the army of sellers. They stand opposed to the buyers like one man, fold their arms in philosophic contentment and their claims would find no limit did not the offers of even the most importunate of buyers have a very definite limit. (22)

Obviously, the ratio of 1 to 10 is, in itself, neither a necessary nor a sufficient condition. This is not the place to find a necessary and sufficient condition in general, yet an attempt to pinpoint the elements required for such a condition can be made with the help of a simple symbolism. This is attempted in a very special case in the appendix. Going back to the exam- 
ple, Marx continues by introducing the buyers' market: "It is well known that the opposite case, with the opposite result, happens more frequently. Great excess of supply over demand; desperate competition among the sellers, and a lack of buyers; forced sales of commodities at ridiculously low prices" (22). Marx's text reveals that, for him, the buyers' market and sellers' market are not contiguous in the sense that between them there is something, but apart from the metaphor of the two armies, his readers are just left with the obvious remark that "in the same proportion in which [competition among the sellers] decreases, the competition among the buyers increases. Result: a more or less considerable rise in the prices of commodities" (22).

The Marxian text continues by introducing long-period considerations, that is, the gravitation of market prices toward prices of production (here Marx uses the expression costs of production) as a consequence of capital migration from (into) those sectors where market prices are below (above) costs of production. Yet in Marx's view, market prices are not to be dismissed lightly as theoretically insignificant. Marx, in fact, goes so far as to claim that the typical market outcome is a market price above or below costs of production, while the equality between the two should be considered an exception:

The determination of price by the cost of production is not to be understood in the sense of the bourgeois economists. The economists say that the average price of commodities equals the cost of production: that is the law. The anarchic movement, in which the rise is compensated for by a fall and the fall by a rise, they regard as an accident. We might just as well consider the fluctuations as the law, and the determination of the price by cost of production as an accident-as is, in fact, done by certain other economists. But it is precisely these fluctuations which, viewed more closely, carry the most frightful devastation in their train and, like an earthquake, cause bourgeois society to shake to its very foundations-it is precisely these fluctuations that force the price to conform to the cost of production. In the totality of this disorderly movement is to be found its order. In the total course of this industrial anarchy, in this circular movement, competition balances, as it were, the one extravagance by the other. (24)

The reader might think that the elder Marx, equipped with an improved understanding of the classical notion of prices of production and with a more mature version of his own theory of labor-value, would not have 
endorsed the foregoing analysis by the young Marx. We think that this is not the case, as witnessed by book 3, chapter 10 of Capital (Marx [1894] 1909). This chapter, bearing the title "Compensation of the Average Rate of Profit by Competition. Market Prices and Market Values. Surplusprofit," is located in part 2, where Marx is confronted with the (insurmountable) problem of reconciling the origin of profit from surplus value with a uniform rate of profit and a uniform rate of surplus value among sectors. This is not the place to provide a thorough assessment of this chapter. It suffices to note the following.

After identifying in II.X.14 the conditions to be met in order that "the prices at which commodities are exchanged with one another may correspond approximately to their values," Marx adds in II.X.15: "[The fact that] the commodities of the various spheres of production are sold at their value implies, of course, only that their value is the center of gravity around which prices fluctuate, and around which their rise and fall tends to an equilibrium." This sentence has been often quoted in the modern literature on gravitation. However, it is not clear whether Marx thinks that the price is unique at each moment of time or, rather, that there is a constellation of prices at each moment of time. The difference is substantial. If sellers and buyers follow mixed strategies instead of pure strategies, there is clearly a constellation of prices at each moment of time. Marx also identifies two simple cases. In the first "demand is so strong that it does not let up when the price is regulated by the value of commodities produced under the most unfavorable conditions" (II.X.16); in this case these conditions determine the market value. In the second, "the mass of the produced commodities exceeds the quantity which is ordinarily disposed of at average market-values" and, as a consequence, "the commodities produced under the most favorable conditions regulate the market value" (II.X.16). Marx is more interested in the result of this process than in the analysis of less simple cases. ${ }^{16}$ However, in II.X.51 he claims:

That side of competition, which is momentarily the weaker, is also that in which the individual acts independently of the mass of his competitors and often works against them, whereby the dependence of one

16. "No matter what may be the way in which prices are regulated, the result always is the following: 1) The law of value dominates the movements of prices, . . 2) The average profit which determines the prices of production must always be approximately equal to that quantity of surplus-value, which falls to the share of a certain individual capital in its capacity as an aliquot part of the total social capital" (II.X.17-18). (All references to Capital give part number, chapter number, paragraph number.) 
upon the other is impressed upon them, while the stronger side always acts more or less unitedly against its antagonist. If the demand for this particular kind of commodities is larger than the supply, then one buyer outbids another, within certain limits, and thereby raises the price of the commodity for all of them above the market-price, while on the other hand the sellers unite in trying to sell at a high price. If, vice versa, the supply exceeds the demand, some one begins to dispose of his goods at a cheaper rate and the others must follow, while the buyers unite in their efforts to depress the market-price as much as possible below the market-value. The common interest is appreciated only so long as each gains more by it than without it. And common action ceases, as soon as this or that side becomes the weaker, when each one tries to get out of it by his own devices with as little loss as possible. (emphasis added)

Here we find a clear echo of the argument used by the young Marx in Wage-Labour and Capital. It is also clear that the price is not unique at each moment of time: on the contrary, there is a constellation of prices at each moment of time. This fact supports our claims that the process needs to be analyzed under the assumption that buyers and sellers follow mixed strategies instead of pure strategies.

\section{Classical Competition and Bertrand Competition}

In the previous sections we outlined the classical notion of competition with particular concern for market price determination. In this section we try to answer the following question: Has the classical notion of competition percolated into modern theory? A positive answer to such a question would allow us to make use of some recent results in order to extend the analysis of market competition within classical economics.

As is well known, in 1883 the mathematician Joseph Louis François Bertrand wrote a review of Léon Walras's Théorie mathématique de la richesse sociale (1883) and Augustin Cournot's Recherches sur les principes mathématiques de la théorie des richesses (1838). ${ }^{17}$ Bertrand was highly skeptical of the then recent blossoming of mathematical economics. In particular, he poured scorn on Cournot's book:

17. An English translation of Bertrand's text, originally in Journal des Savants volume 48, pages 499-508, is provided in the appendix of Magnan de Bornier 1992. 
[Cournot's] formulae, written only in letters, bristle with unknown functions; [Cournot] would consider it outside his field if he were to be more specific. Practical economists must feel that it would be of little value to study such formulae, be they true or false, so they escape from this study by merely closing the book. If Cournot's theory of wealth . . . has failed to attract any serious attention over the past century, it is because the ideas are lost under the profusion of algebraic signs. (quoted in Magnan de Bornier 1992, 647)

As concerns Cournot's duopoly model, Bertrand claimed that, pace Cournot, it admitted "no solution under this assumption" (647), that is, under the assumption that each duopolist tries to undercut the rival in order to attract buyers and stops doing that only when he or she has nothing more to gain from reducing his or her prices. (Note that for Bertrand it is Cournot himself who assumed price competition between the two sellers.) In short, the gist of Bertrand's criticism is that Cournot failed to acknowledge that the envisaged downward movement of prices was limited only by the marginal cost. ${ }^{18} \mathrm{~A}$ somewhat similar charge of indeterminacy was raised sixteen years later by a distinguished economist, Francis Ysidro Edgeworth, in a paper originally published in Italian in 1897 and translated with some modifications into English in 1925. Edgeworth went beyond Bertrand insofar as he claimed that the duopoly model admits a continuous price cycle in the presence of diminishing returns:

[The case of two identical articles] is treated by Cournot as the first step in the transition from monopoly to perfect competition. He concludes that a determinate proposition of equilibrium defined by certain quantities of the articles will be reached. Cournot's conclusion has been shown to be erroneous by Bertrand for the case in which there is no cost of production; by Professor Marshall for the case in which the cost follows the law of increasing returns; and by the present writer for the case in which the cost follows the law of diminishing returns. In the last case there will be an indeterminate tract through which the index of value will oscillate, or rather will vibrate irregularly for an indefinite length of time. (Edgeworth 1925, 117-18; emphasis added)

18. In Bertrand's wording "without limits," but this is only because in Cournot's original example the marginal cost is zero. This is not the place to discuss whether Bertrand's interpretation of Cournot is well grounded or whether Cournot actually used prices instead of quantities as strategic variables: see Magnan de Bornier 1992 and 2001, Dimand and Dore 1999, Morrison 1998 and 2001. 
To defend this claim, Edgeworth produced a numerical example in which two firms compete on prices, but they have capacity constraints. Edgeworth showed there is no (pure strategy) equilibrium in his example and formulated a sort of dynamic solution: firms undercut each other until the price becomes so low that it is convenient for a firm to quote a high price and sell only to the residual demand instead of undercutting the price quoted by the rival. As Edgeworth wrote:

At every stage in the fall of price, and before it has reached its limiting value ..., it is competent to each monopolist to deliberate whether it will pay him better to lower the price against his rival as already described, or rather to raise it to a higher, perhaps the initial, level for that remainder of customers of which he cannot be deprived by his rival (owing to the latter's limitation of supply). Long before the lowest point has been reached, that alternative will have become more advantageous than the course first described. (120)

With the development of game theory and its application to oligopoly models, the so-called Bertrand-Edgeworth competition, explicitly based on price undercutting, became a fruitful and extensively studied alternative to the price-taking competition embodied in the standard perfect competition model (see Baye and Kovenock 2008). Yet the contemporary Bertrand competition model is somewhat different from the original formulation and from the classical notion of competition. First, it is a oneshot game with a mixed strategy equilibrium and not a dynamic process of price undercutting. This feature magnifies the relevance of two missing elements in Smith's and Marx's writings. First is the problem of firms quoting the same price: in the case of a tie the firms fixing the lowest prices must share total demand in one way or another. This requires the introduction of a specific assumption in this regard. Second is the problem of how demand is rationed when a firm's quantity demanded exceeds its capacity. The introduction of a demand rationing scheme is another assumption lacking in the classical authors.

However, a comparison between modern Bertrand competition and Smith's notion of competition, and even more the story told by Marx in Wage-Labour and Capital, magnifies some deficiencies of the former. First, in the former there is a multitude of atomistic buyers described through a demand curve confronted with a given number of sellers, each defined by their costs (generally marginal costs are constant and uniform) and capacity. On the contrary, in Marx we find a sort of symmetry between 
sellers and buyers. It is certainly not difficult to extend the Bertrand competition model to investigate the case in which there is a multitude of atomistic sellers described through a supply curve confronted with a given number of buyers, each defined by their reservation price (possibly constant and uniform) and purchasing power. Generalization to a symmetrical case in which a number of sellers with their costs and selling capacities are confronted with a number of buyers with their reservation prices and buying capacities is certainly less obvious. Second, Bertrand competition theorists have analyzed quite extensively the case of duopoly with constant marginal cost. Few contributions have investigated the oligopoly (see De Francesco and Salvadori 2010 and the literature cited therein). When there are more than two competing firms, many changes are needed. In the case of two firms, any firm can either undercut the other or avoid doing so. In the case of three or more firms, any firm can either undercut all other firms or just some of the firms and not others, or none of them. For example, in the case in which there are two (either equal or not) large firms and a smaller firm, the latter can avoid high prices so that the two large firms are not interested in undercutting it when they undercut each other at higher prices. The small firm can take advantage of this protection from competition with larger firms (at high prices) to obtain a larger rate of profit (see De Francesco and Salvadori 2010, theorem 1(c)). The analysis provided in the appendix may give an idea of the problems involved.

\section{Final Remarks}

In this article we attempted to assess the classical notion of free competition in comparison with the Walrasian notion of perfect competition. We showed that the latter is plagued with some logical difficulties that drastically reduce its explanatory power to equilibrium situations. Such difficulties are absent in the classical notion of competition, which, contrary to the Walrasian one, is not based on any kind of price-taking assumption. Yet the former also displays some unsatisfactory aspects. In particular, while the classical authors extensively investigated long-period, natural values and gravitation, they were more sketchy on market price determination in situations of market disequilibrium. To fill this lacuna we analyzed Smith's and Marx's views on competition between buyers and sellers. We claim that, taking inspiration from the modern theory of Bertrand competition, it is possible both to render Smith's and Marx's hints formally precise and to provide interesting new questions for modern Bertrand competition theorists. 


\section{Appendix 1}

Let $N$ be the number of buyers. Their reservation price is $p_{b}$. Let $B_{1} \geq$ $B_{2} \ldots B_{N}$ be the different quantities of cotton they want to buy and let $B=B_{1}+B_{2}+\ldots+B_{N}$. Similarly, let $M$ be the number of sellers and $c$ their reservation price. Let $S_{1} \geq S_{2} \geq \ldots \geq S_{M}$ be the different quantities of cotton they want to sell and $S=S_{1}+S_{2}+\ldots+S_{M}$. Let us assume that $c<p_{b}$ (the case in which $c \geq p_{b}$ requires more accurate analysis) and that there are no buyers with a reservation price lower than $p_{b}$ and no sellers with a reservation price higher than $c$ (once again, a more accurate analysis would be required otherwise).

If $S<B_{2}+\ldots+B_{N}$, that is, if all buyers but the largest one are willing to buy more than the existing amount of cotton, buyer 1 could be excluded from the purchase and, as a consequence, any other buyer 2, $3, \ldots, N$ could be excluded too. Overbidding among buyers leads the price of cotton to rise to $p_{b}$. Therefore the best strategy for each buyer is to express a demand for cotton at her reservation price and the best strategy for each seller is to quote the price $p_{b}$. On the contrary, if $B>S>$ $B_{2}+\ldots+B_{N}$, that is, if all buyers but the largest one are willing to buy less than the existing amount of cotton even if all buyers are willing to buy more than the existing amount of cotton, buyer 1 knows that she will certainly buy some cotton. In the limiting case in which all buyers $2, \ldots, N$ have purchased their desired amount of cotton, buyer 1 is a monopsonist in relation to the sellers who have not sold their cotton. Let $p_{m}$ be this monopsony price. Obviously, $p_{m}=c .{ }^{19}$ Clearly, if buyers 2, $3, \ldots, N$ quote price $p_{b}$ for cotton, buyer 1 will quote price $p_{m}<p_{b}$. But if buyer 1 quotes price $p_{m}$ for cotton, (some of) the other $N-1$ buyers will outbid her instead of quoting $p_{b}$. Therefore buyer 1 will overbid on them, instead of quoting $p_{m}$. And so on, until the price goes up so much that buyer 1 will prefer again to quote price $p_{m}=c$ and buy only $S-\left(B_{2}+\ldots\right.$ $+B_{N}$ ) units of corn. And so on and so forth. In this situation, sellers cannot "stand opposed to the buyers like one man" and "fold their arms in philosophic contentment": they must fight each other to sell at a higher price.

Similarly, if $B<S_{2}+\ldots+S_{M}$, undercutting among sellers leads the price of cotton to drop to $c$. Therefore, the best strategy for each seller is to quote her reservation price and the best strategy for each buyer is to express a demand for cotton at the price $c$. On the contrary, if $S>B>$

19. Note that if buyers with a reservation price larger than $c$ exist, the monopsony price is larger than $c$. 
$S_{2}+\ldots+S_{M}$, no equilibrium price exists. Nor can an equilibrium price exist if $S=B$, since $S>B_{2}+\ldots+B_{N}$ and $B>S_{2}+\ldots+S_{M}$ : the larger seller has a realistic possibility to sell part of her cotton at $p_{b}$ and the larger buyer has a realistic possibility to buy part of the desired amount of cotton at $c$.

As a consequence, if $B+S_{1}>S$ and $S+B_{1}>B$, both armies, to use Marx's metaphor, are engaged in infighting. The best strategies for both buyers and sellers are not single (i.e., deterministic) prices but distributions of probability within a set of prices.

Determining such distributions of probability requires proper analysis, which is beyond the scope of this article. Besides, to make such calculations we need to make further assumptions not stated by Marx. In particular, we need to know how the residual demand (supply) is determined for sellers (buyers) quoting a price higher (lower) than that quoted by others sellers (buyers) and what happens in the event of a tie. What is certain is that buyer 1 will never quote a price lower than $c$ (the monopsony price if all other buyers are served) or a price higher than $p_{M b}$, defined by the condition that buyer 1 gets the same profit from buying $\min \left\{S, B_{1}\right\}$ at price $p_{M b}$ and buying $S-\left(B_{2}+\ldots+B_{N}\right)$ at price $c$. But, as a consequence, no buyer will quote prices outside the range $\left[c, p_{M b}\right]$. Similarly, seller 1 will never quote a price higher than $p_{b}$ (the monopoly price if all other sellers are served) nor a price lower than $p_{m S}$, defined by the condition that seller 1 gets the same profit from selling $B-\left(S_{2}+\ldots+S_{M}\right)$ at price $p_{b}$ and selling $\min \left\{B, S_{1}\right\}$ at price $p_{m s}$. However, as a consequence, no seller will quote prices outside the range $\left[p_{m s}, p_{b}\right]$. Both arguments make sure that traders can quote only prices that are in both ranges $\left[c, p_{M b}\right]$ and $\left[p_{m S}, p_{b}\right]$.

\section{References}

Arena, R. 1978. "Note sulla concezione classica della concorrenza." Economia e Lavoro, no. 2:323-52.

Arrow, K. J. 1959. “Toward a Theory of Price Adjustment.” In The Allocation of Economic Resources, edited by M. Abramovitz, 41-51. Stanford: Stanford University Press.

Arrow, K. J., and F. H. Hahn. 1971. General Competitive Analysis. San Francisco: Holden Day.

Aspromourgos, T. 2009. The Science of Wealth: Adam Smith and the Framing of Political Economy. London: Routledge.

Baye, M. R., and D. Kovenock. 2008. "Bertrand Competition.” The New Palgrave: A Dictionary of Economics, edited by J. Eatwell, M. Milgate, and P. Newman. London: Macmillan. 
Bellino, E. 2011. "Gravitation of Market Prices towards Natural Prices." In Sraffa and Modern Economics, edited by R. Ciccone, C. Gehrke, and G. Mongiovi, 58-75. London: Routledge.

Bharadwaj, K. 1978. Classical Political Economy and the Rise to Dominance of Supply and Demand Theories. New Delhi: Orient Longmans.

Blaug, M. 1997. "Competition as an End-State and Competition as a Process." In Not Only an Economist: Recent Essays by Mark Blaug, 66-86. Cheltenham: Edward Elgar.

- 1999. "Misunderstanding Classical Economics: The Sraffian Interpretation of the Surplus Approach." HOPE 31:213-36.

— 2001. "No History of Ideas, Please, We're Economists." Journal of Economic Perspectives 15:145-64.

—. 2002. "Ugly Currents in Modern Economics." In Fact and Fiction in Economics: Models, Realism, and Social Construction, edited by U. Mäki, 35-56. Cambridge: Cambridge University Press.

_ 2003. "The Formalist Revolution of the 1950's." Journal of the History of Economic Thought 25:145-56.

- 2009. "The Trade-Off between Rigor and Relevance: Sraffian Economics as a Case in Point." HOPE 41:219-47.

Bradley, M. E. 2010. "Adam Smith's System of Natural Liberty: Competition, Contestability, and Market Process." Journal of the History of Economic Thought 32:237-62.

Ciccone, R. 1999. "Classical and Neoclassical Short-Run Prices: A Comparative Analysis of Their Intended Empirical Content." In Value, Distribution, and Capital: Essays in Honour of Pierangelo Garegnani, edited by G. Mongiovi and F. Petri, 69-92. London: Routledge.

Dardi, M. 1983. "Piero Sraffa (1898-1983)." Quaderni di Storia dell'Economia Politica 3:3-14.

De Francesco, M. A., and N. Salvadori. 2010. "Bertrand-Edgeworth Games under Oligopoly with a Complete Characterization for the Triopoly." http://mpra.ub. uni-muenchen.de/18766/.

Denis, H. 1999. "Marx's Polemics against Steuart." In The Economics of James Steuart, edited by R. Tortajada, 76-83. London: Routledge.

Dimand, R. W., and Mohammed H. I. Dore. 1999. "Cournot, Bertrand, and Game Theory: A Further Note.” Atlantic Economic Journal 27:325-33.

Donzelli, F. 1990. "The Concept of Equilibrium in Neoclassical Economic Theory: An Inquiry into the Evolution of General Competitive Analysis from Walras to the 'Neo-Walrasian Research Programme.'” PhD diss., University of Cambridge.

Duménil, G., and D. Lévy. 1987. "The Dynamics of Competition: A Restoration of Classical Analysis." Cambridge Journal of Economics 11:133-64.

Eatwell, J. 1987. "Classical Competition." The New Palgrave: A Dictionary of Economics, edited by J. Eatwell, M. Milgate, and P. Newman. London: Macmillan.

Edgeworth, F. Y. 1897. "La teoria pura del monopolio." Giornale degli Economisti 40:13-31. 
1925. "The Pure Theory of Monopoly.” In Papers Relating to Political Economy, 1:111-42. London: Macmillan.

Garegnani, P. 1983. "The Classical Theory of Wages and the Role of Demand Schedules in the Determination of Relative Prices." American Economic Review 73:309-13.

- 1984. "Value and Distribution in the Classical Economists and Marx." Oxford Economic Papers 36:291-325.

Giocoli, N. 2003. Modeling Rational Agents: From Interwar Economics to Early Modern Game Theory. Cheltenham: Edward Elgar.

- 2005. "Modeling Rational Agents: The Consistency View of Rationality and the Changing Image of Neoclassical Economics." Cahiers d'Économie Politique, no. 49:177-208.

Green, J. 1974. "The Stability of Edgeworth's Recontracting Process.” Econometrica 42:21-34.

High, J. 2001. "Introduction: Split Personality; A Brief History of Competition in Economic Theory." In Competition, edited by J. High, xiii-xv. Critical Ideas in Economics. Cheltenham: Edward Elgar.

Hollander, S. 1973. The Economics of Adam Smith. Toronto: University of Toronto Press.

Kaldor, N. 1972. “The Irrelevance of Equilibrium Economics.” Economic Journal 82:1237-55.

Kurz, H. D., and N. Salvadori. 1995. Theory of Production: A Long-Period Analysis. Cambridge: Cambridge University Press.

- 2002. "Mark Blaug on the 'Sraffian Interpretation of the Surplus Approach.", HOPE 34:225-36.

- 2010. "In Favor of Rigor and Relevance: A Reply to Mark Blaug." HOPE 43:607-16.

Lavezzi, A. 2003. "Smith, Marshall, and Young on Division of Labour and Economic Growth." European Journal of the History of Economic Thought 10:81-108.

Machovec, F. M. 1995. Perfect Competition and the Transformation of Economics. London: Routledge.

Magnan de Bornier, J. 1992. "The 'Cournot-Bertrand Debate': A Historical Perspective." HOPE 24:623-56.

— 2001. "Magnan de Bornier on Cournot-Bertrand: A Rejoinder to Clarence Morrison." HOPE 33:167-74.

Marx, K. (1847) 1933. Wage-Labour and Capital. New York: International Publishers. —. (1894) 1909. Capital. Vol. 3. Chicago: Charles H. Kerr.

Mas-Colell, A., M. Whinston, and J. Green. 1995. Microeconomic Theory. New York: Oxford University Press.

McNulty, P. 1967. "A Note on the History of Perfect Competition.” Journal of Political Economy 75:395-99.

- 1968. "Economic Theory and the Meaning of Competition." Quarterly Journal of Economics 82:639-56. 
Menudo, J. M., and R. Tortajada. 2009. "Double Competition and Market Stability in Sir James Steuart.” WP ECON 09.06. http://ssrn.com/abstract=1408122.

Morrison, C. 1998. "Cournot, Bertrand, and Modern Game Theory." Atlantic Economic Journal 26:172-74.

2001. "Magnan de Bornier on Cournot-Bertrand." HOPE 33:161-65.

Ricardo, D. 1951. The Works and Correspondence of David Ricardo. Edited by Piero Sraffa, with the collaboration of Maurice Dobb. Cambridge: Cambridge University Press.

Richardson, G. B. 1975. "Adam Smith on Competition and Increasing Returns.” In Essays on Adam Smith, edited by A. S. Skinner and T. Wilson, 350-60. Oxford: Oxford University Press.

Roncaglia, A. 1978. Sraffa and the Theory of Prices. Chichester: John Wiley.

Samuelson, P. A. 1978. "The Canonical Classical Model of Political Economy." Journal of Economic Literature 16:1415-34.

Semmler, W. 1984. "On the Classical and Marxian Theories of Competition, Value, and Prices of Production." Australian Economic Papers 23:130-50.

Smith, A. (1776) 1976. An Inquiry into the Nature and Causes of the Wealth of Nations. Vol. 2 of The Glasgow Edition of the Works and Correspondence of Adam Smith, edited by R. H. Campbell and A. S. Skinner. Oxford: Oxford University Press.

Sraffa, P. 1960. Production of Commodities by Means of Commodities: A Prelude to a Critique of Economic Theory. Cambridge: Cambridge University Press.

Steedman, I. 1984. "Natural Prices, Differential Profit Rates, and the Classical Competitive Process." Manchester School 52:123-40.

Stigler, G. 1957. "Perfect Competition, Historically Contemplated." Journal of Political Economy 65:1-17.

Vickers, J. 1995. “Concepts of Competition.” Oxford Economic Papers 47:1-23. 
